Disponível em

ANRAD http://www.anpad.org.br/rac

RAC, Rio de Janeiro, v. 16, n. 1, art. 6, pp. 98-117, Jan./Fev. 2012

$($ (c) $)$ EY-NC

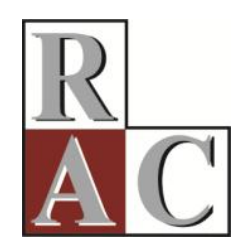

\title{
Representações Sociais sobre as Relações de Parentesco: Estudo de Caso em um Grupo Empresarial Familiar
}

Social Representations of Kinship Relations: a Case Study in a Family Business Group

Carolina Lescura *

E-mail: carolescura@gmail.com Universidade Federal de Lavras - UFLA

Lavras, MG, Brasil.

Mozar José de Brito E-mail: mozarjdb@dae.ufla.br Universidade Federal de Lavras - UFLA

Lavras, MG, Brasil.

Alex Fernando Borges

E-mail: alexfborges@gmail.com Universidade Federal de Uberlândia - UFU Ituiutaba, MG, Brasil.

Mônica Carvalho Alves Cappelle

E-mail: edmo@dae.ufla.br

Universidade Federal de Lavras - UFLA

Lavras, MG, Brasil.

\footnotetext{
* Endereço: Carolina Lescura

UFLA, Campus Universitário, Caixa Postal 3037, Lavras/MG, 37200-000.
}

Copyright (C) 2012 RAC. Todos os direitos, até mesmo de tradução, são reservados. É permitido citar parte de artigos sem autorização prévia, desde que seja identificada a fonte. 


\title{
Resumo
}

O objetivo deste trabalho consiste em compreender as representações sociais acerca das relações de parentesco em grupo constituído por doze organizações familiares do ramo farmacêutico, situadas em uma cidade do Estado de Minas Gerais. Recorreu-se à abordagem teórico-metodológica das representações sociais, para resgatar as representações produzidas pelos diferentes atores sobre a influência das relações de parentesco no cotidiano do grupo familiar. As análises evidenciaram a ocorrência de duas grandes representações: parentesco como integração social e mecanismo de manutenção da ordem organizacional vigente e parentesco como fonte de conflito. Conclui-se que o grupo familiar estudado compartilha, no mesmo espaço, de práticas contraditórias e objetivos diversos, ora atendendo às necessidades empresariais, ora sendo dominado pelos desejos individuais e/ou familiares. Portanto, torna-se complexa a tarefa de ditar fórmulas e modelos analíticos para compreender esses objetos, como o grupo empresarial familiar, pois, em seu cotidiano, suas ações são permeadas de aspectos objetivos e subjetivos, concomitantemente, em dinâmica constante de interação de família com a organização.

Palavras-chave: empresa familiar; família; relações de parentesco; representações sociais.

\begin{abstract}
The purpose of this paper is to comprehend social representations of kinship relations in a group consisting of twelve family firms from the pharmaceutical industry, located in the State of Minas Gerais, Brazil. In addition, the theory of social representations was employed as the methodological approach, in order to uncover representations produced by different actors about the influence of kinship relations on the family group. The results revealed the occurrence of two major representations: kinship as social integration and a mechanism for the maintenance of the established organizational order, and kinship as a source of conflict. We concluded that the family businesses all shared aspects of contradictory practices and diverse objectives; at times focusing on business objectives and needs, while at other times being dominated by personal and/or family desires. As such, it is difficult to develop formulas and analytical models to understand study objects such as the family business group. This is because its actions are characterized by simultaneous subjective and objective aspects, in a constant dynamic of interaction between family and business.
\end{abstract}

Key words: family business; family; kinship relations; social representations. 


\section{Introdução}

Estudos acerca do universo organizacional familiar têm crescido substancialmente nos últimos anos. Além de sua importância socioeconômica, as empresas familiares apresentam certas especificidades que instigam os pesquisadores à compreensão de suas dinâmicas. As duas dimensões, família e empresa, são muito diferentes, o que torna desafiadora a compatibilização entre esses dois universos.

As principais abordagens teóricas da pesquisa sobre empresas familiares mostram focos claramente voltados para estudos referentes aos processos sucessórios, estratégia, profissionalização de gestão, modelos de gestão etc. (Borges, Lescura, \& Oliveira, 2010; Paiva, Oliveira, \& Melo, 2008). Por outro lado, a academia tem dado pouca atenção às dinâmicas subjacentes à organização familiar, sejam elas sociais, emocionais, relacionais, temporais, simbólicas etc. (Davel \& Colbari, 2003). Nesse sentido, torna-se interessante buscar elementos que são incipientes na pesquisa de organizações familiares.

As abordagens sociológicas e antropológicas sobre família e relações de parentesco apresentamse como áreas em potencial na tentativa de compreender a dinâmica desses empreendimentos. Neste sentido, este trabalho possui o objetivo de compreender as representações sociais acerca das relações de parentesco no cotidiano de grupo empresarial familiar constituído por 12 organizações do ramo farmacêutico.

A justificativa deste estudo concentra-se em três aspectos. $\mathrm{O}$ primeiro está relacionado à importância socioeconômica das organizações familiares. Grande parte dos empreendimentos brasileiros pode ser considerada como sendo empresas familiares, responsáveis pela geração de emprego e renda (Leite, 2002). Uma segunda justificativa associa-se ao campo científico, voltado para a investigação de empresas familiares. Apesar de as pesquisas desses objetos terem crescido significativamente, observa-se que os estudos ainda são recentes e frágeis (Paiva et al., 2008). Esse fato pode ser constatado pela própria ausência de um corpo teórico maduro e convergente, identificada na própria diversidade de conceituações existentes. O terceiro aspecto está associado ao fato de a maioria dos estudos serem de cunho funcionalista, concentrando-se em questões econômicas, como crescimento e fatores de sucesso (Grzybovski, 2007). Acredita-se que essa abordagem não seja capaz de compreender as especificidades simbólicas presentes na interação família-empresa. Esses dois sistemas devem ser igualmente considerados na investigação das empresas familiares, pois, segundo Tillmann e Grzybovski (2005), o equilíbrio entre eles é o que garante a sobrevivência desses empreendimentos; portanto este estudo valoriza as investigações da dimensão familiar e das relações de parentesco como suporte para compreender a dinâmica das empresas familiares.

A elaboração deste trabalho exigiu estabelecer recortes em quatro áreas do conhecimento: Administração, Sociologia, Antropologia e Psicologia Social. O enfoque multidisciplinar é uma forma de abordar o fenômeno social sob diferentes prismas de análise. O campo da Administração fornece bases para discutir as teorizações sobre empresas familiares. A área da Sociologia fornece meios para compreender a dinâmica da dimensão familiar. O campo da Antropologia traz discussões das relações de parentesco, permitindo compreender que a maneira de classificar os parentes, dentro de uma estrutura familiar, está imbuída de elementos simbólicos, traduzidos em obrigatoriedades, afetividades e rivalidades. Nesta pesquisa, as organizações familiares são tratadas como espaços capazes de (re)produzir representações sociais de toda a ordem. A Teoria das Representações Sociais é um meio sociológico da Psicologia Social (Farr, 1995), que possibilita apreender, bem como interpretar as diferentes representações sociais produzidas pelos sujeitos investigados.

O artigo foi dividido nas seguintes sessões, além desta introdução: Organizações Familiares e suas Especificidades Simbólicas; a Dimensão Familiar e as Relações de Parentesco; Teoria das Representações Sociais; Metodologia; As Representações Sociais sobre as Relações de Parentesco; Reflexões; e, por fim, Referências. 


\section{Organizações Familiares e suas Especificidades Simbólicas}

As organizações familiares têm sido alvo frequente de investigações por parte de pesquisadores, preocupados em compreender elementos associados à natureza desse tipo de empresa (Poutziouris, Smyrnios, \& Klein, 2006; Sharma, 2006). De modo geral, é possível observar a configuração de uma dinâmica produzida pela conjunção de dois sistemas completamente distintos em suas naturezas e objetivos: a família e a organização. Não obstante, o campo de estudos sobre empresas familiares apresenta uma série de inconsistências, as quais limitam a explicação de elementos teóricos intrínsecos a esses objetos (Debicki, Matherne, Kellermanns, \& Chrisman, 2009).

A questão conceitual tem-se colocado como um dos grandes desafios do campo de pesquisas. Com efeito, o esforço de definição daquilo que constitui, de fato, uma empresa familiar, traz em seu bojo tentativas de agrupar instituições - família e empresa - que apresentam importantes características de diversidade. Neste sentido, existe grande dificuldade de delimitar objetos que se manifestam sob múltiplas facetas e possibilidades, o que acaba por gerar ampla variedade de definições na literatura (Davel, 2008; Litz, 2008). Para Chua, Chrisman e Sharma (1999), o desafio de estabelecer um conceito de empresa familiar reside na tentativa de criação de um único termo para definir esses objetos.

Diante disso, torna-se importante identificar as diferentes definições apresentadas pelos autores da área. Litz (2008) efetuou uma análise dos diferentes conceitos de empresas familiares presentes na literatura. Os principais grupos identificados revelam uma categorização baseada em aspectos como neste elenco: propriedade/controle da empresa sob responsabilidade de membros de uma mesma família; gestão da empresa sob responsabilidade de membros de uma mesma família; propriedade e gestão da empresa sob responsabilidade de membros de uma mesma família; necessidade de continuidade geracional (sucessão).

Com base nos agrupamentos apresentados acima, podem ser classificados conceitos de autores relevantes ao campo de estudos sobre empresas familiares. Uma definição usualmente adotada é de Gersick, Davis, Hampton e Lansberg (1997), em que um empreendimento é de caráter familiar, quando existe conjunção entre propriedade e gestão da empresa nas mãos da família. Este, por sua vez, enquadra-se na perspectiva da interação entre propriedade e/ou gestão da empresa familiar. Outro tipo de definição importante é aquele fundamentado no processo sucessório. Donnelley (1964), em seu texto seminal, afirma que as empresas familiares são aquelas perfeitamente identificadas com uma família há, pelo menos, duas gerações, e que tal ligação exerceria influência recíproca sobre os objetivos da empresa e os interesses da família.

Apesar de tais padrões conceituais serem amplamente utilizados pelos pesquisadores do campo, eles não respondem ao desafio de apresentar definições que dêem representatividade à problemática $\mathrm{e}$ às particularidades das organizações familiares. Litz (2008) aponta que os agrupamentos são falhos, pois, a partir de sua ampla fragmentação, negligenciam a vertente familiar em detrimento da valorização do aspecto empresarial. Ainda, estes conceitos apresentam enfoques em pontos específicos dos ciclos de vida dessas organizações, negligenciando a dinâmica e complexidade características desses empreendimentos.

Sendo assim, surge uma alternativa de definição, baseada na concepção de empresas familiares como um sistema dinâmico de interações da família com a empresa. Litz (2008) aponta uma ilustração dessa dinâmica, quando afirma que uma organização se torna empresa familiar, quando busca apoio em recursos familiares específicos e, para isso, se vincula a uma família ou passa a depender dela. Paralelamente, uma família se torna família empresária, quando procura e recebe apoio de uma empresa, para o alcance de um ou mais objetivos familiares. Partindo dessa perspectiva, podem inserir-se elementos que tornam ainda mais dinâmica a definição de empresas familiares. Grzybovski e Lima (2004) afirmam que empresas familiares são organizações gerenciadas por um grupo de pessoas pertencentes a uma mesma família, que se encontram ligadas, a partir de relações de parentesco, sejam elas estabelecidas por meio de laços genealógicos e biológicos, como por meio de laços sociais. Para 
este artigo, optou-se por adotar esta última concepção, pois acredita-se que ela valoriza a constante interação de família e organização, permitindo a observação da influência da família sobre a gestão, futuro e sobrevivência de organizações familiares.

Com efeito, a interação de família e organização tem sido reconhecida como um dos principais elementos determinantes da dinâmica de empresas familiares (Dyer, 2003; Dyer \& Dyer, 2009). Isso se deve ao fato de que a família exerce influência significativa no desempenho e nas perspectivas de sobrevivência da empresa familiar, contribuindo para a constituição de um tipo singular de organização, em que se fazem presentes elementos econômicos e sociais no âmbito de uma estrutura organizacional (Chrisman, Chua, \& Steier, 2005).

Dyer (2006) identificou diversas variáveis vinculadas à instância familiar, que exercem influência sobre o desempenho de organizações familiares, tais como as práticas de gestão, as particularidades organizacionais e o estilo gerencial do fundador. Assim, o grau de influência da família seria o elemento central que nortearia as práticas de gestão e a formação da cultura da organização familiar. Desse modo, o que pode ser observado nos empreendimentos familiares é que as ligações pessoais e os laços emocionais se apresentam mais intensos, tornando a gestão desses tipos de organização muito complexa.

Esse foco nos aspectos emocionais pode ser explicado por meio da simultaneidade de papéis. Os familiares desempenham papéis de parentes, empregados, diretores, acionistas e/ou detentores potenciais do patrimônio (G. A. V. Silva \& Oliveira, 2008). Apesar dessa simultaneidade de papéis e da tensão existente entre valores e interesses individuais/organizacionais, emergem sentimentos de toda a ordem; portanto trabalhar com integrantes da família envolve, acima de tudo, saber lidar com as emoções presentes nesse universo.

Assim, a dinâmica que fundamenta as organizações familiares pode funcionar como fonte de "coesão, cooperação e comprometimento, mas também como fonte de conflito, rivalidade, discriminação e exclusão" (Davel \& Colbari, 2003, p. 5). Em vista disso, observa-se que o universo das organizações familiares é plural, diversificado, multifacetado, em que coexistem relações de toda a ordem, tanto positivas quanto negativas.

Portanto, ressalta-se a necessidade de compreender as organizações familiares por meio de nova ótica, que valorize e forneça maior respaldo para compreender as suas especificidades simbólicas. É necessário que o pesquisador se abstenha de argumentos tidos como universais, desconstruindo eixos antinômicos (público/privado, racional/emocional, formal/informal). Essas dicotomias perdem sua razão, quando se trata de organizações familiares, dado que, nesses espaços, essas experiências não aparecem de forma separada ou excludente, mas são vivenciadas em uma diversidade de combinações e fusões (Davel, 2008).

\section{A Dimensão Familiar e as Relações de Parentesco}

Para inserir uma discussão acerca do universo familiar, faz-se necessário pontuar algumas teorizações que são debatidas por pesquisadores da área. Verifica-se que os estudos no campo da Antropologia e da Sociologia transpuseram a ideia de família, como fenômeno biológico de conservação e produção, para a visão de família como fenômeno social.

Lévi-Strauss (1896) aponta que a família é uma das formas de organização social mais difundida no mundo, podendo ser encontrada em diferentes sociedades e épocas. Em consonância, Barros (2006) afirma que a família, no decorrer dos anos, foi assumindo diferentes formas. Dessa maneira, é possível encontrar, em uma mesma sociedade, a coexistência de diferentes modelos de sistema familiar, em determinados contextos históricos. 
Bruschini (1990) compreende a família como unidades de relações sociais e de reprodução tanto biológica quanto ideológica, e é nesse espaço que os hábitos, costumes, valores e comportamentos são socialmente construídos. É uma instituição composta por indivíduos de sexos e grupos etários distintos, que interagem cotidianamente, produzindo complexa pluralidade de sentimentos e emoções.

Para Amazonas e Braga (2006), essa estrutura social deve ser tratada por meio de um conceito de trans-historicidade, que desconsidera a estagnação do conceito de família. Para as autoras, nunca existiu a família; o que existe são famílias. Dado que são organizações que interagem com o ambiente no qual estão imersas, verifica-se que as famílias foram sofrendo transformações em decorrência das mudanças demográficas, em especial a maior longevidade humana, a participação crescente da mulher no mercado de trabalho, o divórcio, a diminuição da taxa de fecundidade e as mudanças nos papéis parentais e de gênero. Essas modificações repercutiram diretamente na formação familiar, originando diferentes arranjos familiares, tais como famílias monoparentais, homoparentais ${ }^{(1)}$, coparentais ${ }^{(2)}$, entre outras.

Singly (2007) explica que essas transformações no universo familiar ocorreram a partir dos anos 1960, e acrescenta que o modelo ideal proposto por Talcott Parsons, na década de 1950 - casal, legalmente constituído, com seus filhos, tendo o pai como chefe da família e a mãe como responsável pelos afazeres domésticos e pela educação dos filhos - passou a perder vigor, principalmente no momento em que a mulher desempenha novos papéis, acarretando a tentativa de conciliar o ambiente familiar e a atividade profissional. Essas transformações permitiram uma modificação no calendário familiar, visto que os casamentos ou as uniões passam a acontecer mais tardiamente, bem como os nascimentos; portanto essas recomposições familiares permitem "refundar, de outra forma, a ordem simbólica da família e do parentesco" (Singly, 2007, p. 15).

Compreender o significado da família é relevante, pois permite analisar a dinâmica social desse tipo de organização. A família é constituída pelas estruturas de parentesco, as quais irão determinar as relações familiares; portanto para entender o funcionamento dessa instituição, torna-se necessário tratar deste assunto, de investigação antropológica.

M. Silva (1999) aponta que os estudos de parentesco são importantes para a reflexão sobre linguagem e cultura, pois articula duas ordens consideradas imbricadas: um sistema terminológico, que consiste fundamentalmente em um vocabulário (fenômeno linguístico) e um sistema de atitudes, que representa um código, uma conduta entre os indivíduos unidos pelo laço do parentesco (fenômeno cultural). M. Silva (1999) ressalta que foi Lévi-Strauss, em 1945, o responsável por fundar uma análise não-linguística para os sistemas de parentesco, buscando entender os sentidos que eram atribuídos a essas terminologias, observando a organização e a forma de relacionamento entre os indivíduos com parentesco.

Para Fox (1986), esse sistema representa formas de classificar parentes em categorias e subcategorias (tios, sobrinhos, primos, avós etc.). Essa classificação pode ou não corresponder à realidade social. Ou seja, relações de afinidade com determinadas pessoas, que não representam parentes consanguíneos, podem estabelecer padrões de comportamento muito próximos do que o sistema prescreve. Augé (1978) explica que o parentesco pode ser real, quando o laço social é estabelecido pelo fator biológico; ou mesmo mítico, quando os sujeitos se comportam como parentes, sem possuir nenhum laço de consanguinidade, isto é, existe um comportamento afetivo, de solidariedade, institucionalizado entre eles.

De acordo com Barros (2006, p. 141), o parentesco pode ser compreendido como valor mais amplo e mais difuso do que a família. Como explanado, relações de amizade ou vizinhança se podem estreitar, ultrapassando a barreira biológica de consanguinidade, originando as relações denominadas de "consideração" ou "parentesco de consideração". Para a autora, essa relação, muitas vezes, é duplicada pelo compadrio, que estabelece compromissos e obrigações, estreitando ainda mais as relações. Portanto, verifica-se que as relações de parentesco podem ser concebidas por uma análise mais ampla e complexa, considerando aquelas caracterizadas pelo fator biológico (relações de sangue), aquelas estabelecidas pelos casamentos e as relações de consideração (Barros, 2006). 
O importante para compreender a lógica do parentesco é analisar como se dão as relações entre os integrantes da estrutura familiar, quais são as regras, normas e obrigações necessárias para a manutenção desse sistema. Para Augé (1978, p. 20), o parentesco não representa apenas um princípio de classificação e de organização sistematizado, mas deve ser entendido como código, linguagem "mais ou menos ideológica e mais ou menos manipulada".

Considerando que as estruturas de parentesco delimitam regras e comportamentos entre os indivíduos de uma mesma origem familiar, Radcliffe-Brown e Forde (1982) afirmam que, ao aplicar o termo de parentesco a determinada pessoa, atribui-se, necessariamente, um conjunto de comportamentos, obrigações e atitudes de respeito para com este o sujeito. Adicionalmente, Fox (1986) propõe que os termos utilizados possuem um paralelo com a distribuição dos direitos e obrigações a cada ego individual. As pessoas que são designadas pela mesma linguagem, consequentemente, possuem obrigações semelhantes. Estas regras irão diversificar-se de acordo com o grau de parentesco. Augé (1978) observa que, para parentes mais próximos, as regras são obrigatórias e mais bem definidas do que para parentes afastados.

Assumindo a família como espaço de manifestação simbólica, verifica-se que essa instituição se torna um palco de sentimentos e afetividades múltiplas. Segundo Lopes (2008), a família representa um local de laços marcados por solidariedade, afetividade, segurança e estabilidade. Em contrapartida, é possível encontrar, nesse mesmo espaço, relações conflituosas, competitivas e desagregadoras. Isso evidencia o seu caráter dualístico.

Tendo explorado questões relativas à família e às relações de parentesco, verifica-se que, à medida que esses debates são confrontados com a realidade das empresas familiares, elas passariam a ser visualizadas não apenas como objeto de trabalho e sistema econômico, mas também como expressão de moralidade e valores. Visualiza-se a empresa familiar não como sistema de produção de mão-de-obra, mas como projeto instituído pelo fundador, que deve ser perpetuado para a conservação da tradição de uma família. A organização, permeada pela dinâmica familiar, possui significado simbólico para seus integrantes: o trabalho na organização representa, acima de tudo, a reprodução e a perpetuação de uma cultura familiar no âmbito organizacional.

\section{Teoria das Representações Sociais: uma Abordagem Teórico-Metodológica}

Esta seção tem por objetivo apresentar as representações sociais como recurso teóricometodológico central para efetuação deste trabalho. A teoria das representações sociais foi cunhada pelo psicólogo social francês Serge Moscovici, no ano de 1961, por meio da publicação La Psychanalyse: Son image et son public (como citado em Farr, 1993).

Spink (2004) esclarece que foi no campo da Psicologia Social que as representações sociais deixaram de ter mera função catalisadora, para adquirirem um estatuto de abordagem teórica. A autora explica que tal área do saber fundamenta-se no pressuposto de que o conhecimento é processo e não apenas conteúdo. Nesse sentido, as representações sociais são fruto não apenas de concepções históricas, mas do aqui e agora; são construções que situam o indivíduo, dando-lhe identidade social. Spink (1995) acrescenta ainda que as representações sociais podem ser entendidas como uma espécie de saber prático, porque se inserem, nesse sentido, nas correntes que estudam o conhecimento do senso comum.

Cardoso e Malerba (2000) destacam que a Psicologia Social se preocupa não somente com as representações mentais que acontecem no nível individual, mas como essas representações que ocorrem no sujeito são difundidas, dando origem a uma dimensão mais ampla, denominada de Representação Social. Farr (1995) explica que esse campo se interessa em desvelar a relação entre indivíduo e sociedade; portanto, quando se atribui maior importância a um desses polos, a essência das representações sociais perde a sua vitalidade. 
A ideia cunhada por Moscovici (1961) era a de propor uma interação do nível individual com o coletivo. O sujeito é agente das representações simbólicas que, em ação com outros indivíduos, reproduz algo de maior dimensão: o imaginário coletivo. É por meio das relações sociais que emergem as representações, permitindo ao sujeito a ação de descobrir o mundo, bem como de construí-lo. Assim, a representação social funciona como forma de interpretação da realidade, de leitura, por parte do sujeito, do mundo externo. Essa leitura é interiorizada e processada, reproduzindo comportamentos entre os indivíduos. As representações, quando difundidas, tornam-se representações sociais, as quais dão consistência ao saber prático. Para Spink (1995), as representações sociais, por se constituirem de produtos sociais, devem sempre ser remetidas ao contexto no qual foram produzidas.

Cavedon (2008) explica que as representações sociais são frutos do meio social, por meio do compartilhamento de significados. A subjetividade só é construída e edificada por meio das relações entre os diferentes atores sociais de um determinado grupo, isso porque existe uma significação comum entre eles, e esta foi construída. As representações não são criadas por indivíduos de maneira isolada, mas são constituídas por pessoas e grupos, ao longo da cooperação e da comunicação. Essas representações, à medida que emergem, ganham vida própria, encontram-se, atraem-se, repelem-se, abrindo espaço para o surgimento de novas representações, enquanto outras podem vir a desaparecer. Para Breakwell (1993), as representações são dinâmicas, passíveis tanto de mudanças sutis quanto globais. Essa dinâmica é reflexo da interação constante dos sujeitos produtores de significados.

Pode-se dizer que as representações sociais são compostas por dois processos: objetivação e ancoragem (Arruda, 2002; Franco, 2004; Martins, Trindade, \& Almeida, 2003; Pereira \& Camino, 2003; Ordaz \& Vala, 1997; Xavier, 2002). A objetivação é o processo de tornar um fenômeno objetivado, ou seja, materializado (Ordaz \& Vala, 1997). Em outros termos, é o princípio que torna as noções abstratas em algo concreto, quase tangível (Spink, 1993). A objetivação cristaliza-se "a partir de um processo figurativo e social, e passa a constituir o núcleo central de uma representação, seguidamente evocada, concretizada e disseminada como se fosse o real daqueles que a expressam" (Franco, 2004, p. 72).

Já a ancoragem, pode ser compreendida como processo que transforma o não familiar em familiar (Ordaz \& Vala, 1997), uma forma de atribuir sentido inteligível dentro de dado contexto (Martins et al., 2003). Pode ser entendida ainda como processo de "reconhecimento dos objetos não familiares, com base em categorias previamente conhecidas. Trata-se da atribuição de categorias e nomes à realidade, porque, ao classificar, revelamos nossas teorias sobre a sociedade e o ser humano" (Pereira \& Camino, 2003, p. 448).

Tratando dos aspectos práticos, relacionados à construção das representações sociais, Spink (2004) destaca que as técnicas verbais são as mais utilizadas pelos pesquisadores que buscam apreender as representações, dado que a linguagem exterioriza as significações criadas pelos sujeitos. Jovchelovitch (1995) defende que as análises das representações devem concentrar-se nos processos de comunicação. A comunicação é compreendida como forma de mediação social. Assim ritos, mitos e símbolos tornam-se mediações entre um mundo desconhecido e o mundo da intersubjetividade humana.

\section{Metodologia}

\section{Procedimentos metodológicos}

Para a efetuação deste trabalho, optou-se pela adoção da abordagem qualitativa (Godoi \& Balsini, 2006). Foi realizado um estudo de caso (Godoy, 2006; Yin, 2005) com um grupo empresarial familiar, constituído por doze organizações gerenciadas por filhos, noras e netos do fundador (falecido no ano de 2007). Esses empreendimentos atuam no ramo farmacêutico e estão localizados em uma cidade de médio porte do Estado de Minas Gerais. O caso ilustra um tipo de organização familiar 
comum no Brasil, caracterizada principalmente pelo porte reduzido e pela ausência de distinção entre controle e gestão (Grzybovski, 2007). Neste sentido, pode-se verificar, no caso estudado, que não há separação entre aqueles que detêm a propriedade - família proprietária - e aqueles que gerenciam efetivamente as atividades da organização - família gestora - (Ward \& Dolan, 1998). De fato, a partir da sobreposição sucessiva e constante dos interesses da empresa e dos interesses da família, torna-se a realidade da empresa familiar estudada ainda mais complexa; ela é objeto da pesquisa aqui empreendida.

Este artigo é fruto de um trabalho mais abrangente, em que, além de serem apreendidas as representações sociais do grupo investigado, foi resgatada a história da organização. Como se elucida na sessão anterior, o levantamento de conteúdos históricos é fundamental, para que o pesquisador possa compreender o contexto em que as representações sociais emergiram. O estudo de caso foi fundamentado nas seguintes técnicas de coleta de dados: entrevista semiestruturada e observação nãoparticipante. De acordo com Spink (1995), para atender à proposta das representações sociais é necessário ter em conta, na coleta de dados, longas entrevistas semiestruturadas associadas ao levantamento de conteúdos históricos. Esses conteúdos permitirão compreender os indivíduos enquanto sujeitos sociais. Para tanto a autora recomenda também que sejam ouvidos poucos sujeitos, chamados de sujeitos genéricos, pois terão a finalidade de representar o grupo que está sendo investigado.

As entrevistas foram realizadas com 28 indivíduos, dos quais 7 são dirigentes das filiais, 11 são gerentes e 10 são funcionários de diferentes filiais. As entrevistas contribuíram, de forma efetiva, para a construção das representações sociais atribuídas às relações de parentesco na dinâmica famíliaempresa. É importante esclarecer que, para a construção do presente artigo, nem todos os relatos foram utilizados, sendo escolhidos aqueles de maior relevância para ilustrar o caso. A observação nãoparticipante auxiliou na investigação do ambiente organizacional, identificando como se davam as relações entre os diferentes atores.

O grupo empresarial investigado será denominado de grupo Alfa, a fim de garantir o anonimato. Os entrevistados serão identificados por siglas ou nomes fictícios (Tabela 1).

Tabela 1

Significado dos Códigos Referentes aos Membros do Grupo Familiar

\begin{tabular}{|c|c|}
\hline Código & Descrição \\
\hline Sr. Francisco & Fundador da empresa \\
\hline Sra. Estela & Esposa do fundador \\
\hline D1 & Dirigente filho do fundador \\
\hline D2 & Dirigente filho do fundador - Principal sucessor ( $2^{\circ}$ geração) \\
\hline D3 & Dirigente esposa de D2 \\
\hline D4 & Dirigente filho de D2 e D3 - Sucessor ( $3^{\circ}$ geração) \\
\hline D5 & Dirigente filho de D2 e D3 - Sucessor ( $3^{\circ}$ geração) \\
\hline D6 & Dirigente esposa de D1 \\
\hline D7 & Dirigente filho do fundador \\
\hline G1, G2, G5 & Gerentes da empresa \\
\hline F1 e F5 & Funcionários da empresa \\
\hline
\end{tabular}

Para análise dos relatos apreendidos na pesquisa, Spink (1995) sugere que, inicialmente, se faça a transcrição das entrevistas. Em seguida, é necessário realizar a leitura flutuante do material, intercalando a escuta do material gravado com a leitura do material escrito, a fim de possibilitar a 
emergência dos temas. Depois, tendo já apreendido os aspectos mais gerais da construção do discurso, é fundamental retornar aos objetivos da pesquisa. Para facilitar a visualização do pesquisador, a autora sugere a construção de mapas que possibilitam demonstrar, de modo mais claro, a associação entre as ideias dos entrevistados.

As entrevistas foram gravadas e transcritas na íntegra e, posteriormente, foi realizada uma leitura flutuante. A partir desta leitura, foi construído um mapa de associação de ideias, no qual foi possível evidenciar as representações sociais do grupo investigado. Este mapa não será apresentado neste artigo, visto que a sua finalidade é apenas permitir uma melhor visualização de como as ideias dos entrevistados se associam.

De acordo com Spink (1995), deve-se mapear o discurso nas entrevistas pelos temas emergentes, definidos a partir da leitura flutuante, e guiados pelos objetivos do pesquisador. Os mapas foram elaborados em forma de matriz, o que permitiu relacionar os temas emergentes às representações sociais construídas por representantes dos três diferentes grupos entrevistados: direção, funcionários e gerentes. Ao optar por entender as representações na perspectiva dos grupos e não de indivíduos, buscou-se tanto a diversidade como o que há de comum e compartilhado. Para Spink (1995), essa forma de trabalhar permite preservar a lógica intrínseca da construção de cada sujeito, servindo também como elemento de validação da abstração resultante da junção do conjunto de respostas. A construção dos mapas (matrizes) possibilitou ver a associação de ideias entre os grupos de entrevistados e também analisar a variedade de ideias e imagens presentes em um único grupo.

\section{Breve resgate da história do grupo Alfa}

A trajetória do grupo empresarial familiar do setor farmacêutico tem início com sua fundação, ocorrida no ano de 1965. Em 1960, o fundador (Sr. Francisco) - mesmo sem formação específica na área - começou a trabalhar em uma farmácia local, tendo a oportunidade de adquirir conhecimentos do setor. Assim, o fundador aprendeu a manipular fórmulas de medicamentos e a atender pacientes, práticas muito comuns naquela época. Após cinco anos de atuação nessa empresa, o Sr. Francisco optou por criar seu próprio negócio, abrindo uma pequena farmácia, localizada num bairro da cidade.

Com o passar dos anos, houve um movimento gradativo de entrada dos potenciais sucessores na organização. De modo geral, os filhos entraram ainda adolescentes, conciliando os estudos com o trabalho na empresa, e atuando em atividades operacionais. Assim, os sucessores puderam aprender o funcionamento da empresa, adquirindo competências para, posteriormente, atuarem em atividades de cunho mais estratégico.

Após vivenciar um longo período de expansão das atividades comerciais, a organização enfrentou, entre 1990 e 1992, fortes dificuldades financeiras e um período significativo de retração das atividades, até mesmo com o fechamento de três filiais e a perda de patrimônio da família empresária. Ao mesmo tempo, a relação entre os sucessores começou a se deteriorar, contribuindo para a geração de forte conflito. Houve uma divisão patrimonial, envolvendo as unidades da empresa: de um lado, dois sucessores (D1 e D7) e o fundador (Sr. Francisco) ficaram responsáveis pela administração da matriz; de outro, o segundo sucessor (D2), juntamente com sua esposa (D3), ficaram responsáveis pela condução dos negócios da filial localizada no centro da cidade. A partir de então, esses grupos passaram a seguir trajetórias distintas. Contudo, mesmo com a divisão de propriedade, as duas unidades permaneceram unidas sob uma mesma denominação, já tradicional na cidade. Outro fato importante a ser destacado no decorrer da trajetória do grupo familiar consiste na morte do fundador, ocorrida no ano de 2007, o que influenciou ambos os grupos, dado o reconhecimento e a importância que o fundador possuía junto à organização. 


\section{As Representações Sociais sobre as Relações de Parentesco}

Esta seção busca apresentar as representações sociais construídas pelos atores investigados sobre as relações de parentesco da família empresária. Vale mencionar que, no processo de construção das representações sociais, a objetivação pode ser observada nos muitos casos em que ocorre a interferência das relações de parentesco no processo de gestão do grupo familiar investigado. Já a ancoragem fica explícita no processo de atribuição de sentidos a essas relações de parentesco. Por meio desses elementos, foi possível construir duas grandes representações sociais: Parentesco como integração social e mecanismo de manutenção da ordem organizacional vigente e Parentesco como fonte de conflito.

\section{Parentesco como integração social e mecanismo de manutenção da ordem organizacional vigente}

Pela análise das representações que emergiram das análises foi evidenciado que vários sujeitos da pesquisa interpretam as relações de parentesco como mecanismo social de integração dos familiares. A existência de laços parentais implica união e manutenção de boas relações entre os integrantes da família. Essa representação dá origem a outros significados acerca das relações de parentesco, tais como a afetividade nas relações organizacionais, o respeito entre os membros e a consideração especial por empregados.

\section{Afetividade nas relações organizacionais}

No mapa de associação de ideias que mostra o parentesco como integração social e mecanismo de manutenção da ordem organizacional vigente, tem-se a afetividade nas relações organizacionais. Analisando as representações sociais, pode-se perceber que existe forte laço de afeto entre os integrantes da organização: uma forma de carinho, amizade e proximidade. Essa afetividade, encontrada nas empresas familiares, é tratada em muitos estudos acadêmicos. A interação família/organização possibilita que emoções e sentimentos, próprios do ambiente familiar, sejam vivenciados no espaço organizacional (Davel \& Colbari, 2003). Assim, a gestão desses empreendimentos é caracterizada pela racionalidade substantiva, ou seja, pelo predomínio das emoções, sentimentos e afetos (Macedo, 2002).

Neste sentido, foi possível notar que a afetividade nas organizações Alfa é expressa por meio da proximidade na relação patrão/empregado. Muitos gerentes e funcionários possuem uma relação de amizade com os dirigentes, tornando as relações no espaço organizacional mais harmônicas e menos hierarquizadas. Essas relações não se limitam à empresa, pois é comum que empregados frequentem a casa dos dirigentes, bem como o contrário.

"A gente tem uma proximidade muito grande com os funcionários. Funcionário é amigo nosso aqui. Tem funcionário que você vai na casa dele, ele vai na sua casa" (D4).

A relação no espaço organizacional, caracterizada pela proximidade entre patrão e empregado, faz referência à administração paternalista. Neste tipo de gestão, os funcionários são tratados por seus patrões com uma consideração especial (Forges \& Hamel, 2000).

Como se trata ao longo do trabalho, as organizações familiares apresentam uma forma singular de gerenciamento, mesclando preceitos instrumentais com substantivos, apresentando, em grande parte dos casos, um foco maior nos aspectos emocionais. Assim, a presença da instituição familiar nos negócios possibilita que a dinâmica empresarial seja permeada de aspectos simbólicos, como os sentimentos afetivos. Esses aspectos podem tornar os membros da organização mais unidos, conforme exposto a seguir. 
"porque, quando não tem parentesco, muitas vezes pode ter algum problema. Por exemplo, são dois sócios. Às vezes, os dois não têm parentesco nenhum. Se tem uma discussão ali, acabou. Acho que aquilo ali vai de mal a pior, cada um na sua. A família não, ela briga ali, daqui a alguns dias tá legal de novo. $\mathrm{O}$ sócio discute cada um vai para um canto, não tem parentesco nenhum, não tem aquela afetividade” (G1).

$\mathrm{Na}$ visão de G1, organizações que não apresentam relações de parentesco entre os seus integrantes podem sofrer maiores problemas diante de situações conflituosas. Neste caso, para o entrevistado, as empresas familiares estão em vantagem, pois a presença da afetividade nas relações é capaz de manter os integrantes mais unidos e perpetuando a organização.

\section{O respeito familiar no espaço organizacional}

Pelos mapas de associação de ideias, verificou-se a representação do parentesco como integração social: o respeito entre os integrantes do grupo Alfa. A construção deste trabalho fundamenta-se na interação família/empresa, como principal atributo das organizações familiares. Esse atributo permite compreender que, nesses empreendimentos, comportamentos próprios do ambiente familiar são transferidos para a esfera organizacional. Assim, a construção desta representação partiu do pressuposto de integração família/empresa, pois, por meio das análises, foi possível interpretar que o respeito que existe entre familiares é exercido nas relações empresariais do grupo Alfa. Nesse sentido, verifica-se que o processo de socialização, que envolve os valores cultivados no seio da família, se materializa na questão do respeito entre os sujeitos parentais. A análise dos mapas evidenciou situações específicas que expressam a transposição do respeito familiar para o espaço organizacional. A primeira situação trata da permanência do fundador nas organizações Alfa, mesmo idoso.

"Quando ele [fundador] saiu mesmo da empresa, foi trinta dias antes dele falecer. A gente criava uns horários para ele. Meu pai tinha oitenta e dois anos. Nós criávamos horário para ele, tinha as funções, ele tinha obrigação também dentro da empresa. Você não pode isolar uma pessoa que viveu tantos anos dentro de uma coisa (D2)".

O entrevistado revela que, apesar da idade avançada, Sr. Francisco não foi afastado dos negócios familiares. Isso se dá não apenas pelo carinho e apego do fundador com a organização, mas, sobretudo, por ele possuir uma posição de patriarca, idealizador do negócio, tornando delicado excluílo da organização. Outra situação que expressa o respeito entre os integrantes da família no espaço organizacional foi relatado por um dos funcionários.

“Talvez por ser familiar, eles têm aquele respeito. Tipo, 'mamãe (Sra. Estela) não vai gostar disso'. Até certo ponto, ajuda" (F5).

Existe uma preocupação entre os irmãos em não desapontar a matriarca, Sra. Estela, com desavenças empresariais. Isso denota a integração da família/organização, pois, apesar de a Sra. Estela não atuar no grupo Alfa, os dirigentes evitam maiores conflitos em respeito à figura materna. Embora as situações narradas sejam distintas, é observável a convergência para um único ponto: o respeito aos integrantes mais velhos da família. Portanto, o respeito entre parentes, praticado no espaço familiar, é transferido para o espaço organizacional, independendo da hierarquização dos cargos empresariais.

Outro aspecto, que reforça o respeito familiar no espaço organizacional, é a figura da matriarca, enquanto elemento central para a manutenção do respeito e união entre os irmãos.

“A minha família, hoje, ela ainda é toda centralizada na minha mãe. A minha mãe é viva. Então, minha família é toda centralizada ali. A minha mãe, ela ainda é o pivô de tudo. Os filhos são obrigados a ir lá.

Aí, aquela história, um queixa do outro. Então, ela harmoniza tudo. Ainda hoje a gente pode contar com ela" (D2).

Pelas análises, percebe-se que a Sra. Estela exerce forte influência na dinâmica organizacional, na medida em que atua como mediadora dos conflitos. Ela busca desempenhar, dentro da organização, o mesmo papel que desempenha no âmbito familiar: de manter o bom relacionamento entre seus 
filhos. Harmonizar e obrigar a convivência entre os irmãos, evidenciando a simultaneidade de papéis (G. A. V. Silva \& Oliveira, 2008).

\section{A consideração especial}

A construção desse significado tem analogia com o parentesco de consideração. Como mencionado por Barros (2006, p. 141), as relações de amizade ou vizinhança podem estreitar-se, ultrapassando a barreira biológica de consanguinidade, originando as relações denominadas de "consideração" ou "parentesco de consideração". No grupo Alfa, esse tipo de relação é bastante usual, pois muitas pessoas, que hoje atuam nas organizações, ingressaram há muitos anos, criando laços de carinho e afetividade com a família. Alguns membros, já mantinham relações de amizade antes de mesmo de entrarem para a empresa.

No grupo Alfa, as relações empresariais são caracterizadas pela afetividade. É recorrente a existência de uma relação mais próxima entre patrão e empregado, o que torna o espaço organizacional mais harmônico. No entanto, ao observar a dinâmica do grupo e analisar as falas dos entrevistados, pode-se observar que as relações mais afetuosas dão origem a uma consideração especial, ou seja, alguns empregados, por manterem relações mais próximas com seus patrões, recebem um tratamento diferenciado.

"Tem gerentes aqui que era para ter mandado embora há muito tempo, que você vê que não funciona mais. Que a empresa tá caindo as vendas por causa da atitude dele. Mas, como você vai mandar embora? Ele é da sua família, ele tá há trinta anos aqui dentro da empresa, cresceu com você, viu você cair, viu você levantar. É complicado. São coisas que só acontece em empresa familiar” (D4).

Existem gerentes atuando no grupo Alfa, que não têm desempenho efetivo. Contudo o fato de o sujeito atuar durante muitos anos na organização o tornou uma pessoa familiar. Por isso, nem sempre demitir um funcionário é uma tarefa fácil, pois envolve aspectos simbólicos, como sentimentos e emoções, influenciando as práticas de gestão e a cultura da organização familiar (Colbari, 1996; Dyer, 2006; Souza-Silva \& Davel, 2005).

\section{Parentesco como fonte de conflito}

Uma segunda representação, construída por meio das análises dos mapas de associação de ideias, foi o parentesco como fonte de conflito. O conflito emerge no espaço organizacional, quando coexiste a divergência de interesses entre os atores. A empresa familiar, por abrigar família e organização, passa a ser palco de disputas entre seus membros. A dinâmica dessas empresas revela que os objetivos familiares nem sempre estão de acordo com os objetivos organizacionais, o que gera disputas, rivalidades e conflitos.

A interpretação das narrativas dos dirigentes, gerentes e funcionários do grupo Alfa permitiu a emergência dessa representação social, que é composta por uma rede de significados: duplicidade de comando, centralização das decisões na família empresária e a influência das relações de parentesco nas práticas de recursos humanos.

\section{Duplicidade de comando}

No grupo Alfa, a atuação conjunta de diversos dirigentes, pertencentes à família empresária, contribuiu para a ocorrência de duplicidade de comando nas relações empresariais. Nesse sentido, uma das expressões mais recorrentes entre os entrevistados é que "existe muito cacique para pouca tribo". Essa expressão revela a objetivação, de modo bastante simplista, de um fenômeno complexo que acontece no grupo familiar investigado.

A duplicidade de comando emerge quando duas ou mais pessoas ditam ordens, regras, que, muitas vezes, não apresentam consenso. As análises revelam a insatisfação dos empregados com esse 
tipo de conduta, pois é recorrente a delegação de regras distintas, confundindo os trabalhadores, e, consequentemente, retardando e dificultando a execução das atividades. Uma situação de duplicidade de comando, relatada pelos entrevistados, está relacionada a uma separação conjugal ocorrida com dois dirigentes do grupo Alfa - D2 e D3.

“A separação, por exemplo. Isso reflete direto na empresa. Uns funcionários vão para um lado, uns funcionários vão para o outro" (G2).

A separação de D2 e D3 refletiu diretamente na dinâmica do grupo Alfa. Os gerentes e funcionários, estando cientes do fato, ficavam divididos quando ocorria a delegação de ordens distintas pelo ex-casal. Essa é uma situação muito delicada, que se reflete negativamente na condução dos negócios familiares, denotando mais um produto da interação família/empresa.

\section{A centralização das decisões na família empresária}

A interpretação dos dados permitiu a emergência de uma segunda representação - a centralização das decisões na família empresária (Grzybovski, 2002; Siqueira, Frois, \& Miranda, 1997).

Notou-se que os relatos que evidenciam essa representação partiram do grupo dos empregados que compõem o grupo Alfa. Eles acreditam que, por tratar-se de uma empresa familiar, as decisões ficam concentradas apenas na família empresária, ou seja, nos dirigentes. Talvez os integrantes familiares não deleguem atribuições para os demais empregados, com receio de perder o comando, o domínio das decisões. As falas evidenciam esse fato.

"Eu acho que deveria delegar mais poder ao pessoal que tá no grupo. Porque, quem tá aqui dentro que vê o problema da farmácia, o que deve ser resolvido. Deveria delegar mais poder ao pessoal que é de confiança deles" (G5).

Os gerentes manifestam a insatisfação diante dessa conduta dos dirigentes. Eles possuem uma pseudoautonomia, pois no mesmo tempo em que ocupam o cargo de gerência, não são autorizados a executar todas as funções prescritas para esse cargo. O informante ressalta a importância de delegar poder aos gerentes, pois são eles que vivenciam a realidade organizacional e se defrontam cotidianamente com os problemas organizacionais.

Outro aspecto que evidenciou essa representação é a limitação do plano de carreira. No grupo Alfa, os trabalhadores podem alcançar, no máximo, a função de gerência. No entanto, conforme apresentado no trecho da entrevista, esse cargo não permite ao trabalhador plena autonomia de comando, visto que as decisões ficam concentradas nos dirigentes.

"Deixa a desejar em certas coisas, não tem plano de carreira. O que deixa a desejar a empresa familiar é nessa parte. O plano de carreira não existe, porque o comprador é o filho do homem, o chefe financeiro é a esposa do homem, entende? Fica muito focalizado na parte da família. Você vê que tem até laços familiares nessa parte" (G2).

Os gerentes ficam responsáveis por coordenar cada filial. Contudo essa coordenação acontece de forma bastante superficial, pois não lhes é concedido o direito de executar o controle financeiro, realizar as compras de produtos etc. Essas atribuições ficam a cargo dos dirigentes, ou seja, da família empresária. Diante disso, os gerentes não têm autonomia para direcionar as ações de cada farmácia, o que provoca certa frustração.

\section{A influência do parentesco nas práticas de recursos humanos do grupo Alfa}

O parentesco, seja ele por consanguinidade ou por consideração, tem sido um fator determinante nas práticas de recursos humanos do grupo Alfa. Ao longo da pesquisa de campo, foi possível observar que muitos trabalhadores que atuam na organização ingressaram nos negócios por influência de laços parentais, ou porque mantinham uma relação de amizade com a família empresária. 
Dessa forma, conclui-se que as práticas de recursos humanos sofrem interferência de aspectos pessoais, ou seja, a demissão ou a admissão de um empregado estão relacionadas aos vínculos afetivos, cultivados pela família empresária.

Essa representação possui relação direta com a consideração especial, tratada no item A Consideração Especial, e revelou que pessoas muito próximas da família são tratadas de forma diferenciada, por meio de uma consideração especial, que é capaz de influenciar a conduta dos dirigentes perante seus subordinados. Nesse caso, nota-se que não apenas os laços parentais, mas, sobretudo, os laços de amizade têm influenciado nos processos ligados à área de gestão de pessoas. Pelos mapas de associação ficou evidenciado como as relações de amizade influenciam o processo de admissão dos empregados.

"O cara é bom, então, eu vou colocar o cara ali, ele vai gerenciar aquilo ali... Eles nem sabem se o cara serve para ser gerente. Só porque ele é amigo, ele é gente boa” (G2).

O trecho da entrevista ilustra que questões de nível pessoal são consideradas no momento de admissão de um funcionário, sendo relegado a um segundo plano sua competência para ocupar um cargo. Em consonância, um segundo entrevistado expressa a ideia de que os laços de amizade influenciam na permanência do empregado no grupo Alfa.

"Pra mim, hoje, tem muita gente que estaria fora e muita gente que estaria dentro, por competência e não por questões pessoais. O que acontece é que a pessoa fica por questões pessoais" (F1).

O trecho acima reforça a representação de que, no grupo Alfa, as questões pessoais prevalecem nos processos de admissão e demissão dos empregados. Nesses casos, nota-se que fatores substantivos, como a afetividade entre os sujeitos, se sobrepõe aos atributos de merecimento e competência. A expressão questões pessoais, mencionada por um dos entrevistados, mais uma vez revela o processo de objetivação da influência das relações pessoais na condução das políticas de gestão de pessoas.

A construção dessa representação revelou, mais uma vez, que as organizações familiares possuem uma gestão muito peculiar, fruto da interação família/empresa. A integração entre essas duas dimensões, nesse caso, parece gerar problemas à dinâmica organizacional. Como apresentado, existem muitos empregados que estão atuando no grupo porque são parentes ou amigos da família empresária. Entretanto muitos desses não têm capacidade para ocupar certos cargos, o que prejudica o desempenho das organizações.

\section{Reflexões Finais}

Objetivou-se, no presente trabalho, compreender as representações sociais acerca da dinâmica entre família e organização, particularizando a influência das relações de parentesco no cotidiano do grupo empresarial estudado. Para a concretização deste objetivo foi preciso dialogar com outros campos disciplinares, tais como a Sociologia, a Antropologia e a Psicologia Social. A ideia de estudar as organizações familiares por meio de uma abordagem multidisciplinar, que permitisse a introdução de novas áreas do conhecimento, já foi ressaltada por autores, tanto nacionais, como internacionais. Entretanto, apesar de os estudiosos apontarem para tal necessidade, são poucos os trabalhos que adotam, de fato, novos prismas de análise para investigar esses objetos de estudo.

$\mathrm{Na}$ análise dos resultados, verificou-se a ocorrência de duas grandes representações, que abarcam em seu interior um conjunto de significados. A primeira representação, parentesco como integração social e mecanismo de manutenção da ordem organizacional vigente, revelou aspectos positivos com relação à influência da família nos negócios. Assim, emergiu uma diversidade de significações que evidenciam a integração no espaço organizacional: a afetividade nas relações organizacionais, o respeito entre os membros e a consideração especial por determinados 
trabalhadores. A segunda representação, parentesco como fonte de conflito, também foi constituída por uma rede de significados que denota o conflito no ambiente empresarial: a duplicidade de comando, a centralização das decisões na família empresária e a influência das relações de parentesco nas práticas de recursos humanos.

Toda essa rede de significados, ou associações de ideias, atribuídos a influência das relações de parentesco podem ser estudados em profundidade, pois garantem compreender o conjunto de especificidades que dá sustentação à dinâmica de organizações familiares. A perspectiva teórica e a proposta metodológica utilizadas nesta pesquisa permitiram verificar que a gestão dos empreendimentos do grupo empresarial familiar é constantemente significada e ressignificada pelos grupos de pessoas que trabalham nessas organizações. Além disso, as representações construídas norteiam as ações, os relacionamentos e as formas de interação que ali existem, influenciando os próprios processos organizacionais.

A contribuição da teoria das representações sociais é justamente a de permitir inverter a posição do sujeito na questão do conhecimento: de observador neutro e passivo para um papel central na elaboração das suas representações acerca de uma realidade consensual. Essas construções simbólicas são paradoxais; ora consideram a presença dos laços parentais como algo positivo para a organização familiar, ora como aspecto negativo. Dessa forma, deve-se estar atentos a essas contradições, considerando que esse tipo de organização pode apresentar uma dinâmica muito peculiar, caracterizada por uma multiplicidade de sentidos, os quais influenciam significativamente elementos de cunho familiar e organizacional. Verificou-se que, no grupo familiar estudado, compartilham-se práticas contraditórias, objetivos diversos, que atendem às necessidades e aos anseios empresariais, mas que também são dominados pelos desejos individuais e/ou familiares; portanto torna-se complexa a tarefa de ditar fórmulas e modelos analíticos para compreender objetos como o grupo empresarial familiar, pois suas ações são permeadas de aspectos objetivos e subjetivos, concomitantemente, em uma dinâmica constante de interação da família com a organização.

Esta pesquisa permitiu revelar a dinâmica de um grupo organizacional familiar; portanto não é possível afirmar que a mesma realidade seja encontrada em outros contextos. Existem empresas familiares que apresentam similaridades ou diferenças em relação ao grupo Alfa; entretanto este estudo não foi feito para produzir generalizações. Os próprios resultados encontrados no grupo Alfa podem não ser os mesmos daqui a alguns anos, isso porque a realidade desses empreendimentos não é algo determinável, uma vez que múltiplos significados desvelados, em dado momento, não são estáveis, em termos diacrônicos, sendo suscetíveis de alteração ao longo do tempo. A própria interpretação não é um resultado único; tampouco a interpretação escolhida será mais verdadeira que as demais (Spink, 1995). O que se apresentou aqui foi uma das possibilidades de apreender uma dada realidade.

\section{Artigo recebido em 01.03.2011. Aprovado em 09.11.2011.}

\section{Notas}

\footnotetext{
1 "Homoparental é um termo que surgiu em 1997 para designar uma situação em que pelo menos um dos pais se assume como homossexual" (Derrida, J., \& Roudinesco, E. (2004). De que amanhã... diálogo (p. 48). Rio de Janeiro: J. Zahar).

2 “Coparental é uma situação na qual uma mãe lésbica ou um pai gay elabora o projeto de ter e criar uma criança com um parceiro, sendo que um é o pai biológico e o outro, o pai social que cria a criança” (Derrida \& Roudinesco, 2004, p. 48).
} 


\section{Referências}

Amazonas, M. C. L. A., \& Braga, M. G. R. (2006). Reflexões acerca das novas formas de parentalidade e suas possíveis vicissitudes culturais e subjetivas. Ágora, 9(2), 177-191. doi: 10.1590/S1516-14982006000200002

Arruda, A. (2002). Teorias das representações sociais e teorias de gênero. Cadernos de Pesquisa, 32(117), 127-147. doi: 10.1590/S0100-15742002000300007

Augé, M. (1978). Os limites do parentesco. Lisboa: Edições 70.

Barros, M. L. (2006). Famílias e gerações. Rio de Janeiro: Ed. FGV.

Borges, A. F., Lescura, C., \& Oliveira, J. L. (2010, maio). Empresas familiares: mapeamento da produção científica brasileira no período 1997-2009. Anais do Encontro de Estudos Organizacionais, Florianópolis, SC, Brasil, 6.

Breakwell, G. M. (1993). Social representations and social identity. Papers on Social Representations, 2(3), 198-217.

Bruschini, C. (1990). Mulher, casa e família: o cotidiano nas camadas médias paulistanas. São Paulo: Fundação Carlos Chagas.

Cardoso, C. F., \& Malerba, J. (Orgs.). (2000). Representações: contribuição a um debate transdisciplinar. Campinas: Papirus.

Cavedon, N. R. (2008). Antropologia para administradores (2a ed.). Porto Alegre: UFRGS.

Chrisman, J. J., Chua, J. H., \& Steier, L. P. (2005). Sources and consequences of distinctive familiness: an introduction. Entrepreneurship: Theory and Practice, 29(3), 237-247. doi: 10.1111/j.1540-6520.2005.00080.x

Chua, J. H., Chrisman, J. J., \& Sharma, P. (1999). Defining the family business by behavior. Entrepreneurship: Theory and Practice, 23(4), 19-38.

Colbari, A. (1996). Imagens familiares na cultura das organizações. In E. Davel \& J. Vasconcelos (Orgs.), Recursos humanos e subjetividade (pp. 208-229). Petrópolis: Vozes.

Davel, E. (2008). Em busca do organizacionalmente distintivo no familiar. In A. P. Carrieri, L. A. Saraiva, \& D. Grzybovski (Orgs.), Organizações familiares: um mosaico brasileiro (pp. 9-13). Passo Fundo: UPF.

Davel, E., \& Colbari, A. (2003, setembro). Organizações familiares: desafios, provocações e contribuições para a pesquisa organizacional. Anais do Encontro Nacional da Associação Nacional de Pós-Graduação e Pesquisa em Administração, Atibaia, SP, Brasil, 27.

Debicki, B. J., Matherne, C. F., III, Kellermanns, F. W., \& Chrisman, J. J. (2009). Family business research in the new millennium: an overview of the who, the where, the what, and the why. Family Business Review, 22(2), 151-166. doi: 10.1177/0894486509333598

Donnelley, R. G. (1964). The family business. Harvard Business Review, 42(4), 94-105.

Dyer, W. G., Jr. (2003). The family: the missing variable in organizational research. Entrepreneurship: Theory and Practice, 27(4), 401-416. doi: 10.1111/1540-8520.00018

Dyer, W. G., Jr. (2006). Examining the "family effect" on firm performance. Family Business Review, 19(4), 253-273. doi: 10.1111/j.1741-6248.2006.00074.x 
Dyer, W. G., Jr., \& Dyer, W. J. (2009). Puttting the family into family business research. Family Business Review, 22(3), 216-219. doi: 10.1177/0894486509333042

Farr, R. (1993). The theory of social representations: whence and whinter? Papers on Social Representations, 2(3), 1-9.

Farr, R. (1995). Representações sociais: a teoria e sua história. In P. Guareschi \& S. Jovchelovitch (Orgs.), Textos em representações sociais (2a ed., pp. 31-59). Petrópolis: Vozes.

Forges, E., \& Hamel, J. (2000). O papel da família no desenvolvimento da economia dos "francophones" de Quebec. Revista Organizações e Sociedade, 7(18), 117-123.

Fox, R. L. (1986). Parentesco e casamento. Lisboa: Veja.

Franco, M. L. P. B. (2004). Representações sociais, ideologia e desenvolvimento da consciência. Cadernos de Pesquisa, 34(121), 169-186. doi: 10.1590/S0100-15742004000100008

Gersick, K. E., Davis, J. A., Hampton, M. M., \& Lansberg, I. (1997). De geração para geração: ciclo de vida da empresa familiar. São Paulo: Negócio.

Godoi, C. K., \& Balsini, C. P. V. (2006). A pesquisa qualitativa nos estudos organizacionais brasileiros: uma análise bibliométrica. In C. K. Godoi, R. Bandeira-de-Mello, \& A. B. Silva (Orgs.), Pesquisa qualitativa em estudos organizacionais: paradigmas, estratégias e métodos. (pp. 89-112). São Paulo: Saraiva.

Godoy, A. S. (2006). Estudo de caso qualitativo. In C. K. Godoi, R. Bandeira-de-Mello, \& A. B. Silva (Orgs.), Pesquisa qualitativa em estudos organizacionais: paradigmas, estratégias e métodos. (pp. 115- 146). São Paulo: Saraiva.

Grzybovski, D. (2002). O administrador na empresa familiar: uma abordagem comportamental. Passo Fundo: UPF.

Grzybovski, D. (2007). Plataforma de conhecimentos e aprendizagem transgeracional em empresas familiares (Tese de doutorado). Universidade Federal de Lavras, Lavras, MG, Brasil.

Grzybovski, D., \& Lima, J. (2004, junho). Conceito de família e o dilema metodológico nos estudos sobre empresas familiares. Anais do Encontro de Estudos Organizacionais, Atibaia, SP, Brasil, 3.

Jovchelovitch, S. (1995). Vivendo a vida com os outros: intersubjetividade, espaço público e representações sociais. In P. A. Guareschi \& S. Jovchelovitch (Orgs.), Textos em representações sociais (2a ed., pp. 63-85). Petrópolis: Vozes.

Leite, R. C. (2002). As técnicas modernas de gestão de empresas familiares. In D. Grzybovski \& J. C. Tedesco (Orgs.), Empresa familiar: tendências e racionalidades em conflitos (3a ed., pp. 167198). Passo Fundo: UPF.

Lévi-Strauss, C. (1986). O olhar distanciado. Lisboa: Edições.

Litz, R. A. (2008). Two sides of a one-sided phenomenon: conceptualizing the family business and business family as a möbius strip. Family Business Review, 21(3), 217-236. doi: $10.1177 / 08944865080210030104$

Lopes, F. T. (2008). Fotografias de família: histórias de poder em organizações familiares. (Dissertação de mestrado). Universidade Federal de Minas Gerais, Belo Horizonte, MG, Brasil. 
Macedo, K. B. (2002). Cultura, poder e decisão na organização familiar brasileira. RAE- Eletrônica, l(1), 1-12. doi: 10.1590/S1676-56482002000100014. Recuperado de http://www.scielo.br/pdf/raeel/v1n1/v1n1a14.pdf

Martins, P. O., Trindade, Z. A., \& Almeida, A. M. O. (2003). O ter e o ser: representações sociais da adolescência entre adolescentes de inserção urbana e rural. Psicologia: Reflexão e crítica, 16(3), 555-568. doi: 10.1590/S0102-79722003000300014

Moscovici, S. (1961). La psychoanalyse: son image et son public. Paris: Presses Universitaires de France.

Ordaz, O., \& Vala, J. (1997). Objectivação e ancoragem das representações sociais do suicídio na imprensa escrita. Análise Social, 32(4), 847-874.

Paiva, K. C. M., Oliveira, M. C. S. M., \& Melo, M. C. O. L. (2008). Produção científica brasileira sobre empresa familiar: um metaestudo de artigos publicados em anais de eventos da ANPAD no período de 1997-2007. Revista de Administração Mackenzie, 9(6), 148-173.

Pereira, C., \& Camino, L. (2003). Representações sociais, envolvimento nos direitos humanos e ideologia política em estudantes universitários de João Pessoa. Psicologia e Reflexão, 16(3), 447-460. doi: 10.1590/S0102-79722003000300004

Poutziouris, P. Z., Smyrnios, K. X., \& Klein, S. B. (2006). Introduction: the business of researching family enterprises. In P. Z. Poutziouris, K. X. Smyrnios, \& S. B. Klein (Eds.), Handbook of research on family business (pp. 1-8). Cheltenham: E. Elgar.

Radcliffe-Brown, A. R., \& Forde, C. D. (1982). Sistemas politicos africanos de parentesco e casamento. Lisboa: Fundação Calouste Gulbenkian.

Sharma, P. (2006). An overview of the field of family business studies: current status and directions for the future. In P. Z. Poutziouris, K. X. Smyrnios, \& S. B. Klein (Eds.), Handbook of research on family business (pp. 25-55). Cheltenham: E. Elgar.

Silva, G. A. V., \& Oliveira, L. G. M. (2008). Poder, cultura e racionalidade nas organizações familiares brasileiras. In A. P. Carrieri, L. A. Saraiva, \& D. Grzybovski (Orgs.), Organizações familiares: um mosaico brasileiro (pp. 60-92). Passo Fundo: UPF.

Silva, M. (1999). Linguagem e parentesco. Revista de Antropologia, 42(1-2), 133-161. doi: $10.1590 /$ S0034-77011999000100009

Singly, F. (2007). Sociologia da família contemporânea. Rio de Janeiro: FGV.

Siqueira, M., Frois, E., \& Miranda, D. (1997, setembro). Aspectos culturais em processos sucessórios: estudo em empresas de transporte de passageiros. Anais do Encontro Nacional da Associação Nacional de Pós-Graduação e Pesquisa em Administração, Rio das Pedras, RJ, Brasil, 21.

Souza-Silva, J. C., \& Davel, E. (2005). Formação e aprendizagem pela prática: a força das relações de parentesco por consideração em uma organização de ensino superior. Revista de Administração Pública, 39(1), 43-67.

Spink, M. J. (1993). O conceito de representação social na abordagem psicossocial. Caderno de Saúde Pública, 9(3), 300-308. doi: 10.1590/S0102-311X1993000300017

Spink, M. J. (1995). Desvendando as teorias implícitas: uma metodologia de análise das representações sociais. In P. A. Guareschi \& S. Jovchelovitch (Orgs.), Textos em representações sociais (2a ed., pp. 117-145). Petrópolis: Vozes. 
Spink, M. J. (2004). O estudo empírico das representações sociais. In M. J. Spink (Org.), $O$ conhecimento no cotidiano: as representações sociais na perspectiva da psicologia social. (pp. 85-108). São Paulo: Brasiliense.

Tillmann, C., \& Grzybovski, D. (2005). Sucessão de dirigentes na empresa familiar: estratégias observadas na família empresária. Organizações \& Sociedade, 12(32), 45-61.

Ward, J., \& Dolan, C. (1998). Defining and describing family business ownership configurations. Family Business Review, 11(4), 305-310. doi: 10.1111/j.1741-6248.1998.00305.x

Xavier, R. (2002). Representação social e ideologia: conceitos intercambiáveis? Psicologia e Sociedade, 14(2), 18-47. doi: 10.1590/S0102-71822002000200003

Yin, R. K. (2005). Estudo de caso: planejamento e métodos (3a ed.). Porto Alegre: Bookman. 